\section{P85 (continued)}

Conclusions and Implications: Overall, parents reported positive behavior changes by their families because of their child's participation in the program; with the greatest area of improvement in family awareness of the importance of good nutrition.

Funding: USDA-NIFA Project 2011-67001-30011

\section{P86 Brain Breaks: Physical Activity in the Classroom for Elementary School Children}

Gerd Bobe, PhD, MPH, MS, gerd.bobe@oregonstate.edu, Oregon State University, 307 Linus Pauling Science Center, Linus Pauling Institute, Corvallis, OR 97331; T. Perera, MS; S. Frei, MPH, MA; B. Frei, PhD

Objective: To evaluate "Brain Breaks", an exercise DVD, for promoting physical activity during classroom education in elementary school children.

Target Audience: Elementary school children.

Theory, Prior Research, Rationale: We previously reported that $92 \%$ of Oregon elementary schools do not meet the recommended amount of physical education for at least 150 minutes per week and daily recess. To increase students' physical activity level in schools, we developed an exercise DVD ("Brain Breaks") that provides short physical activity breaks during classroom education.

Description: "Brain Breaks" consists of short segments of physical activity breaks demonstrated by Oregon State University students and athletes and local school children. The segments are subdivided into strength, endurance, and relaxation and stretching activities that can be done in classrooms. Classroom teachers play parts of the DVD at least once per week.

Evaluation: An anonymous mail survey was sent with the exercise DVD to participating Oregon school districts and was returned by 43 elementary school classroom teachers.

Conclusions and Implications: Most elementary school classroom teachers (74\%) played the DVD at least 2-3 times/week; the relaxation and stretching segment was played most often (60\%). Nearly all teachers perceived that classes understood the instructions and responded to them at least adequately (98\%) and that students were excited and engaged in participating (95\% for the relaxation and stretching segment). $91 \%$ of teachers plan to continue using the DVD. In conclusion, "Brain Breaks" was effective in increasing physical activity in elementary school children during classroom education.

Funding: Linus Pauling Institute, USANA

\section{P87 Banking on Strong Bones Curriculum Promotes Behavior Change}

Julie Garden-Robinson, PhD, RD, julie.garden-robinson@ ndsu.edu, North Dakota State University, Department of Health, Nutrition and Exercise Science, EML 351-

Department 7270, Box 6050, Fargo, ND 58108-6050
Objective: The curriculum is designed to increase knowledge/awareness of the role calcium-rich and weightbearing activities play in building and maintaining strong bones among children and to improve food and beverage choices based on Dietary Guidelines recommendations.

Target Audience: Fourth-grade children and their families have participated in the program.

Theory, Prior Research, Rationale: Informed by social cognitive theory, this curriculum uses peer modeling, environmental support and goal-setting to promote behavior change.

Description: An estimated $70 \%$ of pre-teen girls and $60 \%$ of pre-teen boys do not meet the daily calcium recommendation, which places them at risk of developing osteoporosis as adults. A 5-lesson curriculum was designed for use in school classrooms during a 5-week time frame. The program includes hands-on activities, calcium tracking, educational displays, follow-up activities for the teacher, participation incentives using "cow coins" and "cow banks", and optional taste testing activities. Parents/caregivers were provided with weekly newsletters summarizing their child's activities, along with nutrition information, recipes and goal-setting activities.

Evaluation: Pre- and post-surveys of children and parents assessed knowledge gain and achievement of nutrition-related goals. Participants $(n=9,163 ; 49.7 \%$ male) significantly increased their knowledge of calcium sources, indicated preference for milk over soda/pop, increased their self-reported consumption of calciumrich foods and decreased their consumption of sweetened beverages $(\mathrm{p}<.05)$. About $51 \%$ of parents/caregivers reported a positive change in the children's eating habits at home.

Conclusions and Implications: Classroom nutrition education with parent involvement can promote behavior change to increase calcium consumption.

Funding: None

\section{P88 School Food Environment Factors Affecting Fruit and Vegetable School Lunch Waste in Wisconsin Elementary Schools}

Andrea Bontrager Yoder, MM, ayoder@wisc.edu, University of Wisconsin-Madison, 1415 Linden Drive, Madison, WI 53706; L. Foecke; D. Schoeller, PhD

Objective: Assess factors impacting fruit and vegetable (FV) consumption and waste in school lunch.

Study Design, Setting, Participants, and Intervention: Multi-year cross-sectional study in Wisconsin 3rd-5th-graders from schools participating in Farm to School (F2S) programs at differing stages of implementation

Outcome, Measures and Analysis: Digital photographs of student school lunch trays were used to estimate FV items and to calculate cups and percent waste. School lunch menus were used to verify items; preparation types (cooked, raw); menu or salad bar; meal component (entrée, 